\title{
Revolutionary Change
}


Woe to him that claims obedience when it is not due; Woe to him that refuses it when it is.

THOMAS CARLYLE

The nature of things does not madden us: only ill will does.

JEAN JACQUES ROUSSEAU 


\title{
Revolutionary Change
}

\author{
SECOND EDITION
}

CHALMERS JOHNSON

STANFORD UNIVERSITY PRESS

Stanford, California 
First edition published by Little, Brown and Company in 1966

Second edition published by Stanford University Press in 1982

Stanford University Press, Stanford, California

(C) 1982 by the Board of Trustees of the Leland Stanford Junior University

Printed in the United States of America

Cloth ISBN 0-8047-1144-5

Paper ISBN 0-8047-1145-3

Last figure below indicates year of this printing:

0302 OI 00 


\section{Foreword by Bernard Crick}

Even before I read Professor Chalmers Johnson's lucid and important book I had formulated my iron law of revolutions: that revolutions take place because governments break down and not for the reasons that are given out by historians who are hired by the party that happens to emerge into power during the revolutionary situation-reasons that, if I may add obiter dicta to my law, are often taken surprisingly seriously by subsequent social scientists. My iron law is, of course, a tautology. But it is a curious kind of tautology, for whereas in a sense it is obvious that what one means by "revolution" is the breakdown or the breaking down of a government, yet it does tell one something positive: at least where to look. I think I was protesting against so many theories of revolution that concentrate on the ideologies and intentions of the revolutionaries in order to compare them with the sad or glad results. Surely the key is to be found in the pathology of the old order. Quite simply, I meet so many students who have read books on the origins of Communism, Marxism, and the Bolshevik Party, but seem to know little about the Czarist system or the First World War. Tocqueville did not make that mistake. The ideology of the party before the revolution can be, indeed, a formidable clue, among others, as to how it behaves when in power-Hitler's ideology was underestimated on this score; but it is a very poor clue as to how the party comes to power. Contingency and general causes both play a role.

Professor Johnson shows that the physiology and the pathology of politics are quite inseparable. If violence, in his argument, 
is of the essence of a revolutionary situation, it is always "the other side of the coin" of order, or functioning social interaction. So he concentrates his analysis, far more sensibly than in my frivolous and polemical aphorism, on the reasons why social systems break down, why normal social interaction fails in the specific manner we call revolutionary. "The key to both the study and the conceptualization of revolutionary violence," he writes, "lies in social systems analysis." Personally I would prefer to say "clue" rather than "key"; I am not such a Parsonian as Professor Johnson. I cannot always agree that social systems are as fully systematic as the functional analysis always assumes or implies. There are often huge rough edges or glaring "contradictions," which do not always result in collapse, still less revolution; sometimes such unsystematic systems are held together by sheer political will and skill, sometimes one suspects through sheer habit and inertia, even lack of serious challenge. But nonetheless, the model Professor Johnson produces is an excellent model, so long as one remembers that it is a model. It makes us look at the right dimensions and at complicated interrelationships, rather than a simple story either of cause or effect or of intention and result. If the reader will not always give the same value to each of the specified relationships as the author, or always see the real world as quite so systematic, that does not matter: we are saved from either romantic or deterministic error and led to look historically at events and conditions long before "the revolution" as well as afterwards. His table of contents alone is worth brooding over and decoding before plunging into reading the text: it suggests a clear and helpful framework for analysis-even if, like Wittgenstein's famous ladder, we can sometimes kick it over once we have climbed the wall, but then and only then.

Professor Johnson portrays the process of revolution on three levels, "each involving variables that may move a potentially revolutionary situation toward violence or away from violence." These levels are: (i) the level of structural distortion in a social system; (ii) a level of conscious political choice and intention; and 
(iii) the level of strategies and tactics. These, in their historically varying forms, all interact with each other in a revolutionary situation; but this is not just a web of tautologous definition, for he makes clear that these levels can, to an astonishing extent, lead a life of their own. Ideologies cannot be treated, by either a subtle Marxist or a sophisticated Parsonian, as simply a product of social systems: they can be, for example, imports, influential because of a possibly discordant sub-system of intellectuals. And people do not always choose the political tactics most effective for their intentions. There are discussions about means as well as about ends in revolutionary ranks, which are often by no means trivial or predictable in their outcomes. Each instance is different, but we do not have to descend into a purely historical empiricism, as some argue, muttering or incanting that "every case is completely different" or "if you take a long enough view of it, was there really a revolution at all?" Chalmers Johnson gives us an extraordinarily clear and solid framework of analysis-as the great demand for the first edition of this book has shown; but he does not blanch, visibly or otherwise, at the thought that every application of it to an actual circumstance will be different.

Nor is he, on my reading, falling into the trap of some Parsonians of seeming to imply that any functioning social system is to be preferred to any form of instability. This simply does not follow from his analysis. He tells me that I cannot say that a regime is so stable and yet so unjust that I wish it could be overthrown; he is only saying that it is unlikely that revolution will occur unless there is already some demonstrable social instability. A social scientist cannot rule our intentions out of court; but he can legitimately remind us that they are seldom realized in the form that we abstractly conceive them. Orwell once remarked that "all revolutions are failures, but they are not all the same kind of failures." He meant to imply that some are hardly to be counted as failures at all, if judged by realistic standards, not by the idealistic standards of pre-revolutionary speculation.

Most of all, what Professor Chalmers Johnson has clarified for me is the great importance of being sure whether one is talking 
about the pre-revolutionary period (as hindsight sees it); the events of the revolution, or "the Revolution"; or the conduct of government in the post-revolutionary society. And that in each of these periods we have to think in terms of events, ideologies, and policies: separate but interacting factors. Personally I do not find a nine-dimensional box unduly complicated. "Revolution" is not a simple matter. There are no single explanations or theories of revolution. But we can think about them in a less cloudy and more systematic way. In this respect I think students should find this book extremely helpful, and, like a good drink on a hot day, both cooling and stimulating.

Birkbeck College (University of London) 


\section{Preface to the Second Edition}

Since this book was first published in 1966 it has gone through eleven separate printings, been translated into German, French, and Korean, and appeared in a simplified form for foreign readers unfamiliar with Western social science terminology. During that time the world also witnessed at least fifteen revolutions of diverse types. These include the ending during April 1975, with the fall of Saigon, of one phase of the thirty-year-old Vietnamese revolution; the defeat of the Tupamaros in Uruguay; the 1971 revolution that created Bangladesh out of what had been East Pakistan; the military coup of September 1973 against the government of President Salvador Allende in Chile; the leftist military coup of April 1974 in Portugal that led to the end of nearly a half century of authoritarian rule and to independence for Mozambique and Angola; the coup in Cyprus of July 1974 against the government of President Makarios, and the subsequent Turkish invasion of the country that led in turn to the ouster of the regime of General Dimitrios Ioannides in Greece and to the restoration of democratic government after seven years of military rule; the guerrilla war in Rhodesia from 1972 to 1979 and the creation of Zimbabwe during 1980; the military takeover of the government of Ethiopia in the middle of 1974 and the subsequent intervention in Ethiopia by the Soviet Union; the overthrow during July 1979 of President Anastasio Somoza in Nicaragua by the Sandinista revolutionaries after two years of insurrectionary struggle and the loss of more than 50,000 lives; the IRA rebellion in Ulster; the Iranian Revolution from January 
1978 to February 1979; and the emergence of a workers' movement not controlled by the Communist Party in Poland during 1980 and 1981.

And these are only the major cases. During these same fifteen years the world was also assailed by a series of terrorist incidents, some of them revolutionary and some of them not. Significant instances include the shooting of 25 tourists at Lod Airport in Israel in May 1972; the killing of 11 Israeli athletes at the 1972 Olympic Games in Munich; the global epidemic of airplane hijacking; the rise and decline of such groups as the BaaderMeinhof gang in Germany, the Red Army in Japan, and the Symbionese Liberation Army in the United States; and the "revolutionary suicide" of more than 900 people on November 18, 1978, at Jonestown, Guyana. In addition to events such as these, assassinations and assassination attempts, bombings, political kidnappings, and hostage incidents of many kinds (including the seizure of the entire staff of the American Embassy in Teheran for more than a year by Iranian revolutionaries) captured the attention of politicians and political analysts on every continent.

Such evidence that revolution and political violence persist and continue to be major conceptual problems for political scientists suggested the need for a new edition of Revolutionary Change. The original aim of this book was to describe in analytic, social scientific terms what are called "revolutionary situations" and to discuss, again in analytic terms and for purposes of comparing cases, what is likely to happen when an attempt is made to carry out a revolution in either a revolutionary or nonrevolutionary situation. My intent was not so much to create another theory of revolution as to build on the classic studies, such as Crane Brinton's The Anatomy of Revolution, and on my own and others' investigations of particular cases in order to make the insights and conclusions contained in these studies amenable to comparative political analysis. Specifically, I tried to supply the concepts that an analyst would need to determine whether an instance of political violence was really a revolution-regardless of what either incumbent state authorities or insurgents might 
choose to call it-and then to dissect and explain the few genuine cases. This book, then, is not about any particular revolution or the "philosophy" of revolution in general. It is an extended essay in the genre of conceptual clarification; and the primary concepts to be clarified are the "revolutionary situation," "revolutionary action," and "revolutionary change."

In this revised edition I have retained the basic analysis contained in the original version with only minor changes; it appears in the present book as chapters one through seven. In these original chapters I have introduced some new examples, but I have also retained most of the original ones, particularly those that relate to the struggle for civil rights during the 1960's by black Americans. Contemporary readers may experience some difficulty in recalling the murder of Viola Gregg Liuzzo and its significance for social change in America, but this in no way lessens its force as an illustration of what I call "elite intransigence." This period in American life should also serve to remind readers that the problems dealt with in this book are relevant to any social system.

I have omitted the old Chapter Six, "Measuring Disequilibrium," because it digressed too far from the basic purposes of the study. In its place I have put a new chapter on terrorism-its meaning, forms, and relationship to revolutionary struggles. However, I return to one issue posed in "Measuring Disequilibrium" - namely, the need to separate analytically revolutionary situations from revolutions themselves-in a new concluding chapter. This final chapter also includes a summary discussion of the analysis of revolution presented in this book together with an attempt to relate it to some of the other schools of revolutionary interpretation that have become important in recent years.

Chalmers Johnson 
